\title{
The Discussion on Teaching of Vocabulary Based on the Corpus of CET-4 Writing
}

\author{
Si-Mo JIA \\ Shandong Women's University, 2399, University Road, \\ the University Science and Technology Park, \\ Changqing District, Jinan City, Shandong Province, China \\ Simo2007@163.com
}

Keywords: Teaching of English vocabulary, CET-4 writing, Corpus.

\begin{abstract}
The good grasp of vocabulary was beneficial to the improvement of learning of English in all aspects. This paper collected, analyzed and categorized the vocabulary usages in 30 English compositions for test of CET-4 randomly chosen from the Corpus of CLEC. The research found that spelling mistakes and overgeneralization of word's meaning were the main problems concerning with vocabulary which restricted students to score high and to develop specialized and academic English. This phenomenon was caused by three reasons, the unsystematic way in acquiring vocabulary, the little quantity and frequency in exposure to English and the lack of standardization on grammar. Based on these results, this paper provided with several suggestions for the teaching of vocabulary such as to urge students to learn vocabulary in a systematic way, to enforce the quantity of reading and to pay attention to the basic language knowledge in order to steady the memory, system and automatic operational capability of vocabulary.
\end{abstract}

\section{Introduction}

Vocabulary is the most fundamental element composed language, thus, the better acquisition and grasp of vocabulary determine the overall improvement of language ability. During more than half a century, all over the world, many teaching methods adopted different ways in teaching vocabulary; recently, many China linguists also conducted their researches on discussion of methods to teach and to acquire vocabulary efficiently. This paper aimed at providing with suggestions for the teaching of vocabulary for college low-level non-English major students based on the analysis of vocabulary errors in their CET-4 writings. The research found that overgeneralization of meanings and misspellings were the most outstanding problems concerning with vocabulary usage. This paper also analyzed these errors in detail and analyzed the possible reasons led to them, the unsystematic way in acquiring vocabulary, the little quantity and frequency in exposure to English and the lack of standardization on grammar. At last, based on these findings and discussions, this paper put forward with several suggestions for the teaching of vocabulary and language, to teach and learn vocabulary in a systematic way, to enhance the quantity of English reading and to pay attention to the basic language knowledge. As for the limitations of this paper, firstly, more materials could be researched and secondly, the research perspectives could be more comprehensive.

\section{Literature Review}

Lewis in 1993 put forward that the acquisition of vocabulary was the main task of second language acquisition, the development of language skills such as listening, speaking, reading, writing and translation all constructed on the acquisition of vocabulary. Yang in 1999 suggested that the most mistakes foreign language learners made in their writings were concerned with vocabulary. Every method of foreign language teaching paid attention to the teaching and learning of vocabulary (Bahns, 1993).

As for the teaching of vocabulary in main approaches and methods in language teaching, to begin with, to choose the vocabulary to be taught related with the text and to teach them with translation 
and sentence drill, such as the teaching of vocabulary in grammar-translation method and the audiolingual method.

Secondly, to teach vocabulary with objects or actions, such as the way of teaching vocabulary in series method, situational language teaching method and total physical response method. Thirdly, to select the vocabulary taught with the standard of usage frequency, and to teach them within the sentence or dialogue that contextualized, as the way of teaching vocabulary through co-text.

Fourthly, to regard the teaching of vocabulary as the core of the course, to classified the vocabulary into categories and taught them in sequence. Pay attention to the selection of vocabulary to be taught and tried to use less words to compose more sentences. In addition, to split vocabulary into smaller units like lemma, prefix, suffix and etc and to teach vocabulary from the view of wordbuilding (Mochizuki\&Aizawa, 2000)

Fifthly, to teach vocabulary through reading, many studies indicated that the large amount comprehensive input has the additional function of incidental vocabulary acquisition. The first scholar who practiced this method should be Seat and Parmer. In 1953, they published the book A General Service List of English Words and based on this list wrote the teaching material of The New Method Readers. In this book, they firstly lowered the new word rate with 50:1 in their teaching texts , secondly, they made the new word reappear within one text for more than three times, and at last, they made their reading quantity large and numerous(Richards \& Rodgers, 2010).

Another scholar Charles(2007)conducted an empirical research about the incidental vocabulary acquisition in natural reading. He found that the comprehensive natural reading was beneficial to the acquisition of vocabulary in aspects of spelling and meaning, although the word gain was not high, they were important, because they indicated that reading could provide students with the chances to expose to the new vocabulary and assist the partial acquisition, once the learners used the learning strategies of attention, usage and understanding, some knowledge about the new vocabulary could be completely acquired.

At last, as for the teaching of vocabulary in communicative approach, Sokmen(1997)mentioned one sholar studied the direct learning and indirect learning of vocabulary in community language learning. She found that the indirect learning method was beneficial to the learners' vocabulary production ability, especially to the low-level learners, besides, the direct learning was the effective supplementary to the indirect learning in acquisition of the new words.

To sum up, the main approaches for teaching vocabulary were to teach vocabulary through translation, within contextualized sentences or dialogues, relied on real objects or actions, through reading, by lemma, prefix, and suffix, through comprehensive input and by situational discourses.

As for English compositions, they were good materials to observe the conditions and existed problems of learners' grasp and usage of vocabulary. Especially the compositions wrote by lowlevel non-English major students were more valuable to research and could provide with more suggestions for the teaching of vocabulary and language in China.

\section{Methodology}

This paper collected and analyzed the vocabulary usage in 30 English compositions of CET-4, with one same topic, a letter to my friend, randomly chose from the corpus of CLEC. At first, this paper conducted the Error Analysis to these 30 compositions to find out what were the problems concerning with the usage of vocabulary. Secondly, to analyze these errors with empirical cases to find out the reasons led to these problems. At last, based on the above findings and discussions, this paper provided with several suggestions for the teaching of vocabulary and second language in China. 


\section{Results and Findings}

\section{Distribution of Errors in Students' Composition}

Table1. Statistics of Different Kinds of Errors in Students’ Writings

\begin{tabular}{|l|l|l|}
\hline Category & Number & Percentage \\
\hline The Usage of Vocabulary & 130 & 28.02 \\
\hline Forms & 108 & 23.28 \\
\hline Sentence Pattern & 80 & 17.24 \\
\hline Verbs & 69 & 14.87 \\
\hline Pronouns & 29 & 6.25 \\
\hline Collocations & 26 & 5.60 \\
\hline Nouns & 22 & 4.74 \\
\hline Total & 464 & 100 \\
\hline
\end{tabular}

As the statistics reflected in the table above, all together, there are 464 errors appearing in all the 30 compositions and can be classified into 8 categories. Most students make errors about the usage of vocabulary, concerning the aspect of semantic equivalence, 130 errors belonging to this kind appear in the collected material and they take the percentage as 28.02 of all. Next to it is forms. All together, students make 108 errors about the forms of vocabulary in the collected compositions and it takes the percentage of 23.28 to the all. The kind of errors that account the third is about sentence pattern. Students make 80 errors concerning the sentence pattern in all the 30 writings and it takes the percentage of 17.24. The fourth largest kinds of errors are about verbs. Students make 69 errors referring to the correct usage of verbs in all these 30 compositions and it takes the percentage of 14.87. Next is the category of pronouns. 29 errors about the appropriate selection of pronouns appear in students' 30 writings and it takes the percentage 6.25. The last two kinds are collocations and nouns, they separately appear with the number of 26 and 22 and take the percentage as 5.6 and 4.74 .

\section{The Analysis to the Cases about the Usage of Vocabulary}

Firstly, this paper illustrates some typical errors concerning the aspect of semantic equivalence in students' compositions. Most of them can be attributed to the phenomenon of overgeneralization of words' and phrases' meaning. The detailed examples are:

(1) Before we go into society, we must know something about it.

In this sentence, the student intended to express the meaning of getting into the society, graduated form university, began to work, but the phrase go into are the phrase that describes the detailed actions with the directions towards a certain place, such as go into the supermarket or go into the shop.

(2) We can often hear this sentence "Practice makes perfect".

In sentence, the student wanted to express the meaning of hear this proverb or saying, but he or she over generalized the meaning of sentence, sentence concerned more about grammar, not any grammatical unit larger than phrase in any registers all be called as sentence.

(3) For example, in the course of our English study, there is a new word that we didn't learn ago, but we can guess its mean according to our knowledge.

In this sentence, the student over generalized the meaning of ago, although ago and before all expressed the action happened in the past, but there is a difference between the usage of ago and before. Ago always followed time phrase while before followed verb. In this sentence, the students over generalized the meaning of ago but neglect the usage of it. 


\section{The Analysis to the Cases about the Forms of Vocabulary}

As for the errors of misspellings, they were mainly three kinds, at first, the lack or addition of letters in the vocabulary, secondly, the mistakes of letters with similar pronunciation and thirdly, the overgeneralization or under generalization of forms.

\section{The Lack or Addition of Letters in Vocabulary}

As for the lack or addition of letters in the vocabulary, this kind of errors took the largest percentage in errors of misspellings in vocabulary, for example,

(1) We can make good use of our knowledge in the society.

(2) I think everything could do easily after you practice more.

(3) To know more information about the world, I think I should form the good habit of reading newspapers and watching programs of news on TV.

In the first example, the student may had a problem in the pronunciation of the word society, he or she might miss the sound of $/ \mathrm{\partial} /$ in society. So do the second student, missing the sound of $/ \mathrm{I} /$. The last student didn’t memorize the spelling clearly.

\section{Mistakes of Letters with Similar Pronunciation}

As for the cases for mistakes of letters with similar pronunciation,

(1) The most convenient is the public media, we can read the newspaper, listen to the radio, etc.

(2) It is necessary for our college students to get to know the world outside the campus.

(3) If have mastered the technology that the society require.

In these examples, students preliminarily grasped the pronunciation of the vocabulary and what letters or chunk of letters stood what sounds, but they had problems in clearly distinguishing the letters with similar sounds, the word-building and morpheme's functional and semantic meaning.

\section{Undergeneralization or Overgeneralization of Word Forms}

As for the instances of under generalization and overgeneralization of word forms,

(1) The approaches to know about society are various.

(2) For example, in studding English, we need practice more.

(3) We do more reading, listening, writing and so on, we can make rapid progress in English.

In the first two examples, students under generalized rules in plural forms and gender composition, the unmarked plural forms were noun plus $-\mathrm{s}$, but for approach, the plural form was to plus -es. Also, the unmarked tense changed form for verb ended with the letter $-y$ were to change letter-y with the letter -I then plus-ed, like studied, but the present form of the word study was studying. At last, the student over generalized used the rule of repeating the ending letters in the verb whose structure was consonant + vowel + consonant, then plus the present form affix-ing, like putting, he or she over generalized the listening into listening.

\section{Discussion}

In this part, the paper analyzes and illustrates the reasons that led to students' error and provides with some suggestions for the teaching for the vocabulary based on these analysis.

\section{Reasons Led to These Phenomena}

Based on above results and findings, this paper analyzed and summarized three reasons the led to these errors.

Learners haven't learned and acquired vocabulary in a systematic way, they often pay attention to and spend most of the time on memorizing the vocabulary list made for the exam, seldom notice the pronunciation of vocabulary, the correct and appropriate usage of vocabulary, the morphology and lexicology, the functions of affix and etc. these not only cause troubles in their English writings, such as the misspellings and overgeneralization of words' meanings, but also hinder their improvement in listening, speaking and reading as well. Since vocabulary is the fundamental 
element composed the language, the problems in vocabulary limited the overall development of English ability.

Learners' exposure to authentic English material is not enough, they heavily influenced by their first language in expressing themselves with English. When they have a concept in their mind, they couldn't find a good and native-like way to express it in English, for they haven't seen or known how English native speaker express these concepts due to their small exposure to English, both in quantity and frequency, so they often make the errors in substitutions.

The lack of standardization on grammar, from the errors of under generalization and overgeneralization of words' forms, this paper could infer that although some grammar points should be grasped at the high school time, some students still make errors on them at college period.

\section{Suggestions for the Teaching of Vocabulary to College Students}

Based on these discussions, this paper provided with several suggestions for the teaching of vocabulary and language for non-English major students in China.

To require, suggest or provide with ways or classroom activities for students to learn vocabulary comprehensively. To add the teaching link like reading the new vocabulary aloud or dictation to urge students to pay attention to the pronunciation of the vocabulary, to add the questions that tested the real usage of vocabulary with context, to supervise students not only understand or know the words but also notice the example sentences with them and be familiar with their usages.

To enlarge the quantity of reading after class. Since the class time is limited, the teachers could regularly find and scatter some English articles related to students' majors to stimulate their interests and enthusiasm in reading a lot. If condition is permitted, teachers also could discuss about the articles with students on class or require them to write reflections at homework.

To lay the solid foundations for the basic language knowledge. Teachers could themselves notice the students to some grammar points or vocabulary usages that are easily garbled. It is important form students themselves to be aware and avoid these errors when they learn and use English in normal times.

\section{Conclusions}

This paper reviewed and summarized the main approaches for teaching of vocabulary for more than half a century, all around the world. In addition, this paper also reviewed the China recent researches on teaching and acquiring of vocabulary through different ways. This paper collected and analyzed examples concerned with problems in vocabulary usages from 30 CET-4 compositions randomly selected from the corpus-CLEC. The research showed that misspellings and overgeneralization of meaning were two largest and most serious kinds of vocabulary errors. This paper analyzed these two kinds of errors with detailed examples and discussed the reasons that led to these errors. At last, based on these findings and discussions, this paper provided with three suggestions for the teaching of vocabulary and language for low level non-English major students in China, to teach and learn vocabulary in a systematic way, to enhance the quantity of English reading and to pay attention to the basic language knowledge.

\section{References}

[1] Alderson,J. Charles.2007. Judging the Frequency of English words. Applied Linguistics,(28),383-409.

[2] Bahns,J. 1993. Lexical Collocations: A Constrastive View. ELT Journal,(47),56-63.

[3] Ellis, R.1994. The study of second language acquisition. Oxford :Oxford University Press.

[4] Fitzgerald,J.1987.Research on Revision in Writing. Review of Educational Research, (57),481506. 
[5] Ionin,T\&S.Montrul.2010. The Role of L1-Transfer in the Interpretation of articles with definite plurals in L2-English.Language Learning,(60),877-925.

[6] Jack C. Richards \& Theodore S. Rodgers .2010. Approaches and Methods in Language Teaching. Beijing:Foreign Language Teaching and Press \& Cambridge University Press

[7] James,C.2001. Errors in Language Learning and Use Exploring Error Analysis. Beijing:Beijing Foreign Language Teaching and Research Press.

[8] Jarvis,S.2000.Semantic and Conceptual Transfer. Bilingualism: Language, and Cognition,( 3),19-21.

[9] Jeremy Harmer.2011. How to Teach English---An Introduction to the Practice of English Language Teaching. Beijing: Foreign Language Teaching and Press

[10] Meara,P.1984.The Study of Lexis in Interlanguage. In Davies A, Criper,C \& Howatt, A.R.(eds).Interlanguage Paper in Honour of S.Pit Corder.

[11] Mochizuki.M\&K.Aizawa.2000.An Affix Acquisition Order for EFL leaners:An Exploratory Study. System,(28),291-304.

[12] Odlin,T.2005. Crosslinguistic Influence and Conceptual Transfer: What are the Concepts? Annual Review of Applied Linguistics,(25),3-25.

[13] Pawley,A\&Syder,F.1983. Two Puzzles for Linguistic Theory: nativelike selection and native like fluency. In Richards(ed). Language and Communication.

[14] Pulido,D.2007. The Relationship Between Text Comprehension and Second Language Incidental Vocabulary Acquisition: A Matter of Topic Familiarity. Language Learning,(57),155199.

[15] Sokmen,A.1997. Current Trends in Teaching Second Language Vocabulary. In Rechards(ed). In vocabulary: Description, Acquisition and Pedagogy.

[16] Schachter,J.1983. A New Account of Language Transfer. In S.Gass \& L. Selinker (eds,). Language Transfer in Language learning.

[17] Terence Odlin.2001. Language transfer---Cross-linguistic influence in language learning. Cambridge: Cambridge University Press. 